\title{
INTRODUZINDO A POLÍTICA NA CRECHE: A EDUCAÇÃO INFANTIL COMO PRÁTICA DEMOCRÁTICA ${ }^{12}$
}

\section{Peter Moss}

Resumo: Este artigo explora a possibilidade de que instituições de educação infantil possam ser, antes de tudo, locais de prática política - e especificamente de práticas políticas democráticas. A necessidade de uma primazia de práticas políticas democráticas em instituições de educação infantil se faz mais urgente por conta de dois fenômenos evidentes em muitos países atualmente: o aumento do interesse governamental na educação infantil, conduzindo a uma expansão do atendimento, e a necessidade de revitalizar políticas democráticas. Assim como a introdução da prática democrática na creche, o que significaria e quais condições a possibilitariam,o artigo também considera a prática democrática em outros níveis: não só o institucional, mas também o nacional ou federal, o regional e o local, e como cada nível pode criar "espaços democráticos" em outros níveis. Por fim, o artigo considera quatro questões relacionadas à democracia na educação infantil incluindo a diversidade paradigmática e o nível europeu.

Palavras-chave: Cidadania. Práticas democráticas. Educação infantil. Creches. Práticas políticas.

\section{Introdução}

Um livro recentemente publicado, intitulado Ethics and Politics in Early Childhood Education (Ética e Política na Educação Infantil), começa com as seguintes palavras:"Este livro trata de uma possibilidade para instituições de crianças e jovens... A possibilidade é de que essas instituições possam ser entendidas, antes de tudo, como

1 Este artigo foi originalmente publicado em European Early Childhood Education Research Journal, 2007, 5(10), 1-19.

2 Tradução de Carolina Brum e revisão técnica de Fernanda Müller e Ana Carvalho. 
fóruns, espaços ou locais para a prática ética e política" (Dahlberg \& Moss, 2005, pp. 1-2).

Este artigo explora parte dessa proposta: a possibilidade de que instituições para crianças e jovens possam ser, antes de tudo, locais de prática política - e especificamente de prática política democrática. Seu foco é um conjunto de instituições, aquelas para crianças abaixo da faixa etária da educação obrigatória. Mas o argumento aplica-se igualmente a outros tipos de instituições, incluindo escolas para crianças maiores. $O$ artigo também utiliza o termo "educação infantil" como simplificação para uma ampla gama de instituições provedoras de educação e cuidado de crianças, incluindo berçários, creches, pré-escolas e centros para crianças e famílias. Em outras palavras, "educação" é tratada como um conceito amplo que engloba aprendizagem, cuidado e formação - "educação em seu sentido mais amplo".

Quando afirmo que há uma possibilidade de que instituições para crianças e jovens possam ser, antes de tudo, lugares de prática política democrática, quero dizer "possibilidade" para enfatizar que esse entendimento é uma escolha que nós, como cidadãos, podemos fazer. Não há nada de inevitável nisso: há mais de uma maneira de pensar e manter essas instituições. É possível que elas sejam entendidas como lugares de prática democrática. Mas há outras possibilidades.

Instituições de educação infantil podem, por exemplo, ser pensadas como lugares, antes de tudo, para práticas técnicas: lugares onde a sociedade pode aplicar tecnologias humanas poderosas às crianças para produzir resultados predeterminados. Sob esse aspecto, elas fazem parte do que Allan Luke descreve como uma "visão internacionalmente desmedida de escolarização, ensino e aprendizagem baseada meramente na eficácia sistêmica da produção técnica avaliada do capital humano" (Luke, 2005, p. 12). Ou, para dar outro exemplo, elas podem ser pensadas como um negócio competindo em um mercado privado e oferecendo mercadorias aos pais-como-consumidores.

Esses entendimentos são ambos muito proeminentes na Inglaterra. A pergunta-chave sobre educação infantil é extremamente técnica:"o que funciona?", enquanto o plano recente de ação do governo para a implementação de sua estratégia de dez anos para o cuidado de crianças é claramente baseado em uma abordagem de mercado (English Department for Education e Skills. Department for Work and Pensions, 2006a). O documento se refere à necessidade "de desenvolver em todas as áreas um mercado próspero de cuidado de crianças que responderá às 'necessidades' dos pais"; à "distribuição através do mercado" e a como autoridades locais terão que "desempenhar um papel ativo no entendimento do modo pelo qual o mercado local de cuidado de crianças está funcionando" e ajudar "o mercado a funcionar mais eficazmente". Não há referência alguma à "democracia". 


\section{A necessidade de práticas democráticas}

Por que práticas democráticas são tão importantes, no geral e na educação infantil? A necessidade pode ser posta em poucas palavras. Participação democrática é um critério importante de cidadania: é um meio pelo qual crianças e adultos podem se envolver com outros na tomada de decisões que afetam eles mesmos, grupos dos quais eles são membros e a sociedade como um todo. É também um meio de resistir ao poder e à sua vontade de governar, e às formas de opressão e injustiça que emergem do exercício descontrolado do poder. Por fim, mas não menos importante, a democracia permite que a diversidade prospere. Ao fazer isso, oferece o melhor ambiente para a produção de pensamentos e práticas novas.

A meu ver, a necessidade da primazia de prática política democrática em instituições de educação infantil se faz mais urgente por conta de dois fenômenos evidentes em muitos países atualmente. Primeiramente, há o aumento do interesse político na educação infantil, conduzindo a uma expansão do atendimento. A questão, portanto, do que pensamos ser o objetivo das instituições de educação infantil, e a que propósitos elas servem em nossas sociedades, está se tornando muito urgente.

Especialmente no mundo anglo-saxão, a resposta - a base para ação - é predominantemente técnica e consumista. Como mencionado anteriormente, instituições de educação infantil são facilmente vistas como lugares para governar crianças por meio da aplicação de tecnologias humanas cada vez mais poderosas, e como provedoras de mercadorias a serem negociadas no mercado de cuidado de crianças. Essa concepção de atendimento para crianças é produzida pelo que foi denominado por Dahlberg e Moss (2005) um discurso anglo-americano, um discurso que é instrumental na racionalidade, técnico na prática e marcado por certos valores: escolha individual e competitividade, certeza e universalidade. Esse discurso tem outra característica que está em desacordo com uma ideia de prática democrática: ele é inerentemente totalizador. Ele não entende que pode ser apenas uma das maneiras de ver e entender, que poderia haver outras maneiras de exercer e avaliar a primeira infância, que poderia haver mais de uma resposta correta para qualquer questão, que essa é apenas uma de muitas perspectivas.

Se esse discurso fosse limitado ao mundo anglo-saxão, isso já seria sério. Mas suas aspirações são maiores: é cada vez mais dominante em outros locais, como pode ser julgado pela disseminação de seu vocabulário preferido, com termos como "qualidade" e "resultados". Esse é um exemplo daquilo a que Santos (2004) se refere como"globalização hegemônica",que é "a globalização bem-sucedida de um local particular e um discurso culturalmente específico a ponto de fazer alegações de verdade universais e 'restringir' todos os discursos rivais" (p. 149). O que possibilita esse discurso aspirar à dominância global é a disseminação da língua inglesa e de valores e crenças neoliberais. 
O neoliberalismo almeja despolitizar a vida, reduzindo tudo a questões de valor monetário e cálculos, práticas de gerenciamento e técnicas. Prefere questões técnicas a questões críticas e, sob sua influência, vemos o surgimento daquilo a que Clarke (1998) se refere como"políticas gerenciadas" em um "estado gerenciador":

Os problemas que o estado gerenciador se propõe a resolver derivam de contradições e conflitos nas esferas política, econômica e social. Mas o que temos visto é o gerenciamento dessas contradições: elas são redefinidas como "problemas a serem gerenciados"'Termos como"eficiência"e "eficácia,"'execução" e "qualidade" despolitizam uma série de questões sociais... e, então, transferem práticas reais e escolhas políticas para imperativos gerenciáveis. (p. 174)

Isso leva ao meu segundo argumento sobre a importância contemporânea das práticas democráticas para instituições de educação infantil. O processo de despolitização na vida pública pode ser visto como parte de um processo mais amplo: a democracia ou, eu diria, as instituições estabelecidas e as práticas de democracia representativa, estão em um estado debilitado. Menos pessoas votam, representantes eleitos são vistos com pouco apreço, seções inteiras da comunidade sentem-se excluídas da política em voga, enquanto muitos outros se sentem céticos ou desinteressados e forças políticas não-democráticas vêm ascendendo. Ao mesmo tempo, no entanto, nem tudo são trevas; há razões para esperança. A alienação das forças políticas democráticas mais tradicionais e formais - políticos, partidos políticos e instituições políticas - é compensada pelo interesse e comprometimento crescente em outras formas de políticas democráticas, incluindo comprometimento direto com movimentos ativos em questões particulares, tais como o meio ambiente ou a globalização.

O desafio é tanto reviver políticas democráticas tradicionais ou formais quanto explorar o interesse em formas alternativas de política democrática, através do desenvolvimento de novos lugares e temas para a prática da política democrática - incluindo instituições de educação infantil e temas que são centrais para a vida diária das crianças e adultos que participam dessas instituições.

\section{Democracia em vários níveis}

A primeira parte do título desse artigo se refere a 'introduzir a política na creche". Mas a segunda parte - "educação infantil como prática democrática" - implica práticas democráticas em vários níveis: não só o institucional, a creche, mas também o nacional ou federal, o regional e o local. Cada nível é responsável por certas escolhas - e é importante deixar claro nesse ponto que eu uso a palavra "escolha" para significar o processo de- 
mocrático das tomadas de decisão coletivas, para resgatar dos neoliberais o uso da palavra "escolha" como tomada de decisão de consumidores individuais. Como afirma uma reportagem recente da democracia britânica - 0 Power Inquiry (2006):

Nós não acreditamos que o consumidor e o cidadão são o mesmo, como a nova tecnocracia dirigida pelo mercado assume. Consumidores agem como indivíduos, tomando decisões baseados pricipalmente em como uma questão os afetará e às suas famílias. Cidadania implica o pertencimento a um coletivo onde as decisões são tomadas não só pelo interesse do indivíduo, mas do coletivo como um todo ou de uma parte significativa desse coletivo. (p. 169)

As escolhas feitas em cada nível devem ser democráticas, a consequência da prática política democrática. Mas cada nível deve também apoiar práticas democráticas em níveis mais locais, garantindo que esses tomem decisões importantes e sejam apoiados ao fazê-lo - em outras palavras, criando "espaços democráticos" e condições para práticas democráticas ativas.

Qual é o espaço democrático em nível nacional ou federal? Quais escolhas democráticas devem ser feitas nesse nível? A tarefa aqui é oferecer uma estrutura nacional de direitos, expectativas e valores que expressem objetivos e crenças nacionais democraticamente aceitos; e oferecer as condições materiais para torná-los realidade e para possibilitar que outros níveis executem e pratiquem a democracia. Essa estrutura necessita ser tanto clara quanto forte, sem sufocar a diversidade regional ou local. Para exemplificar, isso significa: direito claro de acesso ao atendimento para crianças como cidadãos (no meu ponto de vista, desde os 12 meses de idade), juntamente com um sistema de apoio financeiro que possibilite a todas as crianças exercerem seus direitos; uma declaração clara de que os atendimentos para as crianças pequenas são bens e responsabilidade públicos, não uma mercadoria privada; uma estrutura curricular que defina valores e objetivos amplos, mas permita interpretação local; uma política para a infância totalmente integrada, sob responsabilidade de um departamento de governo; uma força de trabalho bem educada e bem paga para todas as crianças pequenas (pelo menos metade da qual deve ter formação superior); e práticas ativas para reduzir a pobreza e a desigualdade.

Um contraste interessante pode ser feito entre o meu próprio país, a Inglaterra, e os países nórdicos. Desde 1997, o governo da Inglaterra tem levado a infância muito mais a sério do que fazia antes. Uma série de meIhorias foi realizada, incluindo a integração da responsabilidade pelo atendimento às crianças dentro do Departamento de Educação e o desenvolvimento de Centros Infantis, como forma integrada de provisão. Um currículo também foi introduzido. 
Mas isso ainda é muito distante do tipo de estrutura referida acima, e adotada nos países nórdicos: não apoia as práticas democráticas.

O currículo existente para crianças de 3 a 5 anos, com um total de 128 páginas, é altamente prescritivo e ligado a mais de 60 objetivos de aprendizagem inicial (Qualifications and Curriculum Authority [QCA], 2000). Um novo currículo, abrangendo crianças desde o nascimento até os cinco anos, teve uma versão preliminar publicada e é tema de discussão (English Department for Education and Skills. Department for Work and Pensions, 2006b). Também é longo, detalhado e prescritivo. Contém, segundo calculou um crítico estrangeiro, mais de 1500 conselhos específicos aos professores, alguns na forma de diretrizes, outros apontando marcos de desenvolvimento específicos aos quais os profissionais devem dedicar-se. Ao invés de princípios, valores e metas amplos, abertos à interpretação por profissionais de confiança, como nos países nórdicos, a versão preliminar do currículo é entendida como um manual para técnicos: ele não cria "espaço democrático" e não encoraja a prática democrática.

Outro contraste é evidente entre os currículos na Inglaterra e nos países nórdicos. Wagner (2006) defende que a democracia é central para o conceito nórdico de boa infância e aponta, em apoio a essa afirmação, que "documentos da política oficial e diretrizes curriculares nos países nórdicos reconhecem uma expectativa central de que pré-escolas e escolas exemplificarão princípios democráticos e de que crianças serão participantes ativos nesses ambientes democráticos" (p.292). Alguns exemplos nacionais ilustram esse ponto. Em sua parte inicial, os currículos da pré-escola sueca (apenas 19 páginas em sua tradução para o inglês) discutem "valores fundamentais" da pré-escola, iniciando essa seção com uma afirmação clara: "a democracia forma a base da pré-escola. Por esse motivo, todas as atividades da pré-escola devem ser realizadas de acordo com valores democráticos fundamentais" (Swedish Ministry of Education and Science, 1998). O novo currículo norueguês (34 páginas) fala sobre educação infantil assentando "a base para ... a participação ativa na sociedade democrática" (Norwegian Ministry of Education and Research, 2006). Esse objetivo ecoa no guia curricular nacional da Islândia para as pré-escolas (47 páginas), o qual alega que um dos objetivos essenciais da educação na pré-escola é "assentar as bases para possibilitar que [as crianças] sejam independentes, reflexivas, ativas e cidadãs responsáveis em uma sociedade democrática"; o guia acrescenta posteriormente que "as práticas democráticas devem ser ensinadas à criança na pré-escola" (Icelandic Ministry of Education, Science and Culture, 2003, p.7, 18).

Já os currículos ingleses existentes ou recentemente esboçados sobre os primeiros anos não contêm referências à democracia, apesar de sua maior extensão. Assim, enquanto os currículos nórdicos reconhecem explicitamente a democracia como um valor, os currículos ingleses não o fazem. Esses são exemplos claros de como a tomada de decisões em nível nacio- 
nal pode apoiar a democracia em outros níveis, através de documentos de políticas que afirmam inequivocamente que a democracia é um valor nacionalmente aceito - e que criam "espaços democráticos"em níveis mais locais para interpretação democrática da política nacional, nesse caso, de currículos nacionais. Evidentemente, há na Inglaterra muitos exemplos de instituições individuais que praticam democracia. Mas a ausência de democracia em documentos-chave de políticas nacionais reflete a prioridade dada à prática técnica e às políticas gerenciadoras, e as consequências da compreensão de grande parte da educação infantil como negócio que vende um produto.

Passo agora para o nível local de governo. Ao fazê-lo, estou consciente de omitir um nível de governo estadual, provincial ou regional que é importante em muitos países, por exemplo, Alemanha, Austrália, Canadá, Espanha e Estados Unidos. Uma discussão completa sobre práticas democráticas na educação infantil teria de levar em conta esse nível de governo, localizado entre o nacional e o local. No entanto, esse artigo o evitará em função da falta de espaço, mas também de falta de conhecimento pessoal, proveniente que sou do país mais centralizado da Europa.

Já sugeri que um sistema democrático envolve cada nível deixando espaço para práticas democráticas em outros níveis. Isso significa forte descentralização para o nível local (Power Inquiry, 2006). O que a prática democrática nas instituições de educação infantil envolve nesse nível?

Há alguns anos, visitei uma cidade italiana com uma rica experiência em educação infantil. Os coordenadores do atendimento nessa cidade que, por acaso, não é Reggio Emilia - descreveram seu trabalho, de mais de 30 anos, como "um projeto cultural local de infância". Esse termo mantevese comigo porque captura o que há de melhor e mais eficiente na prática democrática a ser alcançada por uma autoridade local, comuna ou município. Captura aquela ideia de compromisso político, a participação dos cidadãos e a tomada de decisão coletiva que pode capacitar uma comunidade a ter responsabilidade sobre suas crianças e sua educação (no seu sentido mais amplo), responsabilidade não só por oferecer atendimento, mas por como ele é entendido, pelos propósitos a que serve naquela comunidade e para a prática pedagógica que combina com ele. Algumas outras comunas italianas (incluindo, mas não só, Reggio) comprometeram-se com esses empreendimentos coletivos e democráticos e, sem dúvida, há exemplos em outros países.

Há outras formas de pensar sobre tais projetos locais: como ato utópico, experimentação social ou pesquisa e ação de comunidade. O que todos esses termos têm em comum é a ideia da comuna como criadora de um espaço para o questionamento democrático e diálogo a partir do qual uma visão coletiva sobre a criança e sua relação com a comunidade é produzida, desenvolvendo a política local, a prática e o conhecimento. Isso, por sua vez, está sempre aberto à avaliação democrática e a novos modos 
de pensar. Em alguns casos, esses projetos podem ser ativamente incentivados pelo governo nacional; em outros, como na Itália, eles podem ser viabilizados por um governo nacional fraco e governos locais com tradições democráticas fortes, dispostos e capazes de usar um espaço que lhes é disponibilizado - não intencionalmente, mas pela omissão do governo central.

De que forma projetos culturais locais de infância podem ser ativamente incentivados, que outras condições eles necessitam para prosperar e que estruturas e processos podem sustentá-los são temas muito importantes para a pesquisa sobre a prática democrática na educação infantil. Não deveríamos esperar que esses projetos aconteçam em todas as áreas locais - não se pode legislar por elas. Mas, mesmo onde eles não acontecem, a prática democrática pode desempenhar uma importante função no nível do governo local. As autoridades locais deveriam exercer um papel importante na interpretação de referenciais nacionais, tais como documentos curriculares. Elas podem afirmar a importância da democracia como valor e apoiar a democracia na creche. As autoridades podem também fomentar outras condições favoráveis para a democracia, por exemplo, construindo ativamente a colaboração entre serviços - sob forma de redes, não mercados; ou fornecer um arquivo de documentação, cuja importância na prática democrática será discutida abaixo.

Por fim, quero considerar a prática democrática nas próprias instituições de educação infantil: trazer a política para a creche - ou escolinha, pré-escola, jardim de infância, berçário ou qualquer um dos outros termos que descrevem contextos de educação infantil coletiva. $O$ ponto de partida deve ser de que forma imaginamos, construímos ou entendemos essa instituição: o que entendemos por creche? Já mencionei dois entendimentos comuns, pelo menos no mundo anglo-saxão:a instituição de educação infantil como um recinto onde a tecnologia pode ser aplicada para produzir resultados pré-determinados (a metáfora é a fábrica); e a instituição de educação infantil como negócio, vendendo uma mercadoria aos consumidores.

Mas há muitos outros entendimentos, sendo alguns mais geradores de práticas democráticas: em particular, a instituição de educação infantil como um fórum público na sociedade civil ou como um canal de encontro e diálogo entre cidadãos, do qual muitas possibilidades podem surgir, algumas já esperadas, outras não, havendo maior produtividade quando as relações são governadas pela prática democrática. Essa imagem está ricamente expressa em For a New Public Education System, declaração lançada no verão de 2005 na 40 Escola de Verão Rosa Sensat, em Barcelona. Aqui o termo "escola" é usado como um termo genérico para designar instituições para todas as crianças, tanto na idade de escolaridade obrigatória quanto abaixo dela. 
No novo sistema de educação pública, a escola deve ser um lugar para todos, um lugar de encontro no sentido físico, social, cultural e político da palavra.Um fórum ou lugar para se encontrar e se relacionar, onde crianças e adultos se encontram e se comprometem com alguma coisa, onde dialogam, ouvem e discutem para partilhar significados. É um lugar de infinitas possibilidades culturais, linguísticas, sociais, estéticas, éticas, econômicas e políticas.Um lugar da práxis ética e política, um espaço para a aprendizagem democrática. Um lugar para a pesquisa e a criatividade, coexistência e prazer, reflexão crítica e emancipação. (Associació de Mestres Rosa Sensat, 2005, p. 10)

A instituição de educação infantil na qual as políticas democráticas - juntamente com a ética - são práticas prioritárias cria um dos novos espaços necessários para que haja uma renovação da democracia. Particularmente, ela oferece uma prática democrática que não é representativa (através da eleição de representantes), mas direta: o governo de todos por todos. Esse espaço oferece oportunidades a todos os cidadãos, os jovens e os mais velhos, para participarem, sejam eles filhos ou pais, profissionais ou políticos, ou, na verdade, qualquer outro cidadão local. Assuntos ignorados ou negligenciados na política tradicional podem se transformar em questões da prática democrática.

Trazer a política democrática para dentro da creche significa o engajamento dos cidadãos em pelo menos quatro tipos de atividades. Em primeiro lugar, a tomada de decisões sobre as intenções, as práticas e o ambiente da creche. Em segundo, a avaliação do trabalho pedagógico através de métodos participativos. No livro Beyond Quality in Early Childhood Education and Care (Dahlberg, Moss, \& Pence, 1999) os autores contrastam "qualidade" como uma linguagem técnica de avaliação com uma linguagem democrática:"fazer sentido". Em terceiro lugar, contestar discursos dominantes, o que Foucault chama de regimes da verdade, que procuram dar forma às nossas subjetividades e práticas através de suas pretensões de verdade universal e de sua relação com o poder. Essa atividade política procura tornar contestáveis pressupostos e valores fundamentais.

Yeatman (1994) refere-se a essa terceira atividade como uma "política pós-moderna" e oferece alguns exemplos: uma política da Epistemologia, contestando a visão moderna do conhecimento; uma política de representação, sobre de quem são as perspectivas que têm legitimidade; e uma política da diferença, que conteste os grupos que reivindicam uma posição privilegiada de objetividade sobre um tema controvertido. Mas poderíamos ampliar as áreas abertas à política, que são repolitizadas como temas legítimos para diálogo e contestação política inclusivos: a imagem da criança, a qualidade de vida que queremos para nossos filhos; o que a educação pode e deveria ser; o gênero na creche e em casa. Esses e muitos outros temas podem ser objeto do engajamento democrático dentro da instituição de educação infantil, exemplos do trazer a política para dentro da creche. 
É por meio da contestação dos discursos dominantes que a quarta atividade política pode emergir: uma abertura para a mudança através de visões utópicas e sua transformação em ação utópica. Pois, como Foucault (1988) também assinala, há uma ligação estreita entre contestar discursos dominantes, pensar de maneira diferente e mudar: "tão logo alguém não consiga mais pensar como pensava anteriormente, a transformação tornase ao mesmo tempo muito urgente, muito difícil e razoavelmente possível."

\section{Condições para a democracia}

É improvável que a instituição de educação infantil como um local para a prática democrática ocorra por acaso. É necessário que haja intenção, uma escolha precisa ser feita, e isso requer condições favoráveis. Já me referi à importância da imagem da instituição, mas outras imagens ou compreensões também são importantes para introduzir a política na creche, como, por exemplo, a imagem da criança, de pais e de funcionários. A criança é entendida como um cidadão competente, um especialista em sua própria vida, tendo opiniões que são dignas de serem ouvidas e tendo o direito e competência para participar da tomada de decisões coletiva.É importante reconhecer, também, que crianças (e adultos) têm uma centena de linguagens para se expressarem, e prática democrática significa ser capaz de "ouvir" essas linguagens. Os pais também são vistos como cidadãos competentes "porque têm e desenvolvem suas próprias experiências, pontos de vista, interpretações e ideias que são os frutos de sua experiência como pais e cidadãos" (Cagliari, Barozzi, \& Giudici, 2004, p. 30). Profissionais assumem o que Oberhuemer (2005) chama de "profissionalismo democrático",compreendendo seu papel como praticantes da democracia. Embora reconhecendo que introduzem uma perspectiva importante e um conhecimento local relevante para o fórum democrático, eles também reconhecem que não detêm o acesso verdadeiro ou privilegiado ao conhecimento.

A prática democrática requer que determinados valores sejam compartilhados na comunidade da instituição de educação infantil, por exemplo:

- respeito à diversidade, que está relacionado à ética de um encontro, uma ética relacional destacada por Dahlberg e Moss (2005) em sua discussão sobre ética na educação infantil;

- reconhecimento de múltiplas perspectivas e paradigmas diversos - de que há mais de uma resposta para a maioria das questões e de que existem muitas formas de visualização e compreensão do mundo, um ponto para o qual eu vou retornar; 
- acolher a curiosidade, a incerteza e a subjetividade - e a responsabilidade que essas exigem de nós;

- pensamento crítico, que, nas palavras de Nikolas Rose, é "uma questão de introduzir uma atitude crítica em relação às questões que em nossas experiências atuais são tomadas como se fossem atemporais, naturais, incontestáveis: defender-se contra as máximas de um tempo, contra o espírito de determinada época, contra a sabedoria contemporânea recebida... [é uma questão] de interromper a fluência das narrativas que codificam essa experiência e fazê-las gaguejar."(Rose, 1999, p. 20)

A importância de tais valores para o cultivo da prática democrática é apreendida nas palavras de três pedagogos de Reggio Emilia, no que se refere à participação em suas escolas municipais:

A participação é baseada na ideia de que a realidade não é objetiva, de que cultura é um produto da sociedade em constante evolução, de que conhecimento individual é apenas parcial; e de que, para construir um projeto, cada ponto de vista é relevante no diálogo com as opiniões dos outros, dentro de um quadro de valores partilhados. A ideia de participação baseia-se nesses conceitos: em nossa opinião, portanto, também o é a própria democracia. (Cagliari et al., 2004, p. 29)

Tanto quanto concepções e valores, a prática democrática nas instituições de educação infantil requer certas condições e ferramentas materiais. Uma mão-de-obra bem qualificada, educada para o exercício democrático da profissição é um exemplo importante. Outro exemplo pode ser o papel do amigo crítico, como o pedagogo do norte da Itália, um professor experiente trabalhando com um pequeno número de centros para dar apoio ao diálogo e ao pensamento crítico sobre a prática pedagógica. Um terceiro exemplo é a documentação pedagógica, por meio da qual práticas e processos de aprendizagem se tornam visíveis e, assim, sujeitos ao pensamento crítico, ao diálogo, à reflexão, à interpretação e, se necessário, à avaliação democrática e à tomada de decisões.

A documentação pedagógica desempenha um papel central em muitas facetas da instituição de educação infantil: a avaliação, o desenvolvimento profissional, a pesquisa e a prática democrática. Malaguzzi observou isso nesse contexto democrático, segundo o que escreveu seu biógrafo, Alfredo Hoyuelos (2004):

[Documentação] é uma das chaves para a filosofia de Malaguzzi. Por detrás desta prática, creio, está o conceito ideológico e ético de uma escola transparente e de uma educação transparente... uma ideia política também emerge, a de que as ações das escolas devem ter visibilidade pública... Documentação, em todas as suas diferentes formas, também representa uma ferramenta extraordinária para o diálogo, para a troca, para a partilha. Para Malaguzzi isto significa a 
possibilidade de discutir e dialogar "com tudo e com todos" (professores, auxiliares, cozinheiros, famílias, administradores e cidadãos.) Partilhar opiniões por meio da documentação pressupõe estar apto a discutir coisas reais e concretas, não apenas teorias ou palavras, sobre as quais é possível chegar a um acordo fácil e ingênuo. (p.7)

Carlina Rinaldi (2005) também fala da documentação como prática democrática:"compartilhar a documentação significa participar de um verdadeiro ato de democracia, dando suporte à cultura e à visibilidade da infância, tanto dentro como fora da escola: participação democrática, ou 'democracia participativa', é um produto do intercâmbio e da visibilidade" (p. 59).

Atualmente, a documentação é amplamente praticada sob diversas formas e com vários propósitos. Um exemplo com qual estou muito familiarizado é a abordagem do Mosaico desenvolvida por minha colega Alison Clark. Inspirada pela documentação pedagógica, a abordagem do Mosaico vem sendo utilizada com uma variedade de intenções, inclusive a de permitir a participação de crianças no planejamento de novos prédios e espaços externos. Esse é mais um exemplo de como a documentação pedagógica é uma ferramenta essencial para a prática democrática - nesse caso, a contribuição de crianças para a tomada de decisões (Clark, 2005; Clark \& Moss, 2005).

É importante ter em mente que documentação pedagógica não é observação das crianças; não é um meio de obter uma imagem real do que crianças podem fazer nem uma tecnologia de normalização. Por exemplo, a documentação pedagógica não pressupõe uma verdade objetiva ou externa sobre a criança que possa ser registrada e representada com precisão. Em vez disso, adota os valores da subjetividade e da multiplicidade: nunca poderá ser neutra, é sempre uma perspectiva (Dahlberg et al., 1999). Entendida dessa forma, como um meio de explorar e contestar diferentes perspectivas, a documentação pedagógica não apenas torna-se um meio de resistir ao poder, incluindo discursos dominantes, mas também de promover a prática democrática.

O tempo impede que se discutam outras condições e ferramentas para a prática democrática, exceto trazer à tona o que me parece uma questão muito importante: o próprio tempo. A prática democrática na creche, como em qualquer lugar, toma tempo e o tempo é curto hoje em dia, quando estamos incessantemente ocupados. Um elemento estranho da política inglesa quanto à primeira infância, mas também quanto à idade de escolaridade obrigatória, é a ênfase dada ao "envolvimento dos pais" quando os pais parecem estar mais ocupados do que nunca. Então, por um lado, a política valoriza o trabalho para pais e mães e, ao mesmo tempo, valoriza que os pais estejam envolvidos na educação de seus filhos e no serviço de atendimento que frequentam. Existe uma tensão interessante aqui embora menos que poderia parecer à primeira vista, se a política entende 
envolvimento basicamente como o apoio dos pais a objetivos e metas tidos como já estabelecidos; o envolvimento entendido como uma prática democrática crítica exige mais tempo. Nessa medida é necessário pensar mais sobre a questão do tempo e como poderíamos redistribuí-lo em um conjunto de atividades e relacionamentos. Ulrich Beck (1998), por exemplo, comenta esse ponto quando propõe o conceito de "trabalho público" que forneceria um "novo foco de atividade e identidade que revitalizará o modo democrático de vida" (p.60), e sugere diversas formas de pagar por trabalhos públicos.

\section{Quatro observações conclusivas}

Concluirei fazendo quatro observações sobre a minha visão de educação infantil como uma prática democrática - ou de que ela é possível. Em primeiro lugar, estabelecer a democracia como um valor central nas instituições de educação infantil é, de acordo com o meu ponto de vista, incompatível com a consideração dessas instituições como negócio e a adoção de uma abordagem mercadológica para o desenvolvimento do atendimento. Negócios, ou pelo menos aqueles pertencentes a um indivíduo ou empresa, podem, evidentemente, querer ouvir seus "clientes" e levar seus pontos de vista em consideração. Podem até mesmo exercer alguma responsabilidade social. Entretanto, não podem permitir que a prática democrática seja uma prática prioritária porque sua responsabilidade principal é para com seus proprietários ou acionistas; as decisões nos negócios não podem ser tomadas democraticamente. Da mesma forma, um sistema de atendimento às crianças baseado em escolhas feitas por consumidores individuais está fundamentalmente em desacordo com outro sistema que valoriza decisões coletivas tomadas pelos cidadãos. O Power Inquiry (2006) faz essa distinção claramente:"decisões individuais tomadas em benefício próprio e da própria família não podem substituir a deliberação em massa no domínio público, que é um processo absolutamente crucial numa sociedade democrática e aberta" (p. 159).

Em segundo lugar, a democracia é arriscada. Ela pode representar uma ameaça não só para os poderosos, mas também para os que são fracos. As pessoas vêm para o processo democrático não só com diferentes perspectivas, mas também com poderes e interesses diversos; é provável a ocorrência de conflitos em que os mais fracos poderão perder. A desigualdade pode então aumentar ao invés de diminuir. Um argumento contra a descentralização, que o governo inglês pode muito bem utilizar em defesa de uma abordagem altamente centralizada e prescritiva à política, é que uma forte regulamentação central da educação infantil é necessária para garantir a igualdade de tratamento para todas as crianças; sem isso, abremse as portas para a desigualdade, arriscando algumas crianças a obterem 
condições muito piores que as outras - um risco maior para as de origem mais pobre. Há certa verdade nisso: a defesa da menor centralização e de mais prática democrática é mais fraca numa sociedade desigual, onde a educação infantil e sua força de trabalho são menos desenvolvidas e foram alvo historicamente de desinteresse e baixo investimento público.

Não há uma resposta final e definitiva para esse dilema. A tensa relação entre unidade e descentralização, padronização e diversidade é antiga e nunca resolvida em definitivo - é uma eterna dialética, uma relação em fluxo constante e uma questão política sempre contestável. Conforme implícito acima, tudo isso precisa ser decidido em relação às condições atuais, mas também em relação a onde se deseja chegar. Mesmo julgando que a atual situação requer uma forte centralização, pode-se decidir que não é isso que se deseja a longo prazo. Então, a questão é que condições são necessárias para avançar em direção à descentralização e à democracia. Esse processo de movimento da centralização para a descentralização pode ser observado na história da educação infantil na Suécia, que passou de uma abordagem bastante centralizada e padronizada para uma abordagem que atualmente é fortemente descentralizada. Mesmo assim, a relação deve estar sempre sob um escrutínio minucioso. Como a descentralização está funcionando na prática? Quem se beneficia e quem perde? Como a prática democrática pode ser mais bem equilibrada no que se refere a um tratamento equitativo?

Minha terceira observação diz respeito à questão do paradigma. Propus, anteriormente, que o reconhecimento de diversos paradigmas é um valor importante para a prática democrática. Mas, atualmente, tal reconhecimento é raro. Em vez disso, o mundo da infância enfrenta uma questão profundamente inquietante, mas, em grande medida, não explicitada: a divisão paradigmática entre a maioria (seja a daqueles que fazem a política, dos profissionais ou dos pesquisadores), que está situada num paradigma positivista ou modernista, e a minoria, que se situa num paradigma diversas vezes descrito como pós-moderno, pós-positivista ou pós-fundacional. A primeira desposa "a visão moderna de verdade como reflexo da natureza... [e acredita] que o conflito de interpretações pode ser mediado ou resolvido de modo a proporcionar uma única teoria coerente que corresponda à forma como as coisas são" (Babich, Bergoffen, \& Glynn, 1995, p. 1). Enquanto os últimos adotam "questões pós-modernas de interpretação, avaliação e perspectiva... [e] uma realidade infinitamente interpretável onde interpretações diversas, divergentes complementares, contraditórias e não comparáveis contestam-se mutuamente" (p. 1). Para os primeiros a educação infantil está avançando inexoravelmente para sua apoteose, baseada na crescente capacidade da ciência moderna de fornecer evidências irrefutáveis sobre o que funciona melhor. Enquanto, para os últimos, a educação infantil oferece um prospecto de infinitas possibilidades, informadas por múltiplas perspectivas, conhecimentos locais e verdades provisórias. 
Os dois lados têm pouco a ver um com o outro. A comunicação é restrita, dado que os modernistas não reconhecem paradigmas, aceitando sem questionamento seu próprio paradigma e seus respectivos pressupostos e valores. Enquanto os pós-modernistas reconhecem paradigmas, mas dão pouco valor ao paradigma da modernidade ou, pelo menos, optaram por não se situar nele. O primeiro grupo, por conseguinte, não vê uma escolha a fazer; já o outro fez uma escolha que envolve situá-lo além da modernidade.Comunicações emitidas a partir de um campo são rejeitadas pelo outro por serem consideradas inválidas, incompreensíveis, desinteressantes ou fantasiosas.

Essa relação distante e não-comunicativa faz alguma diferença? $\mathrm{O}$ papel dos pós-fundacionalistas não é desenvolver discursos alternativos e pensamento crítico, ao invés de confraternizarem-se com aqueles com os quais parecem não ter nada em comum? E não deveriam os modernistas concentrar sua atenção no que acreditam, na produção do verdadeiro conhecimento? Penso que faz diferença. A ausência de diálogo e debate empobrece a primeira infância e enfraquece a política democrática. As políticas e práticas "dominantes" ficam isoladas de uma fonte importante de pensamentos novos e diferentes; aqueles que fazem a política têm pouca ou nenhuma consciência de que há um movimento crescente questionando muito do que eles tomam como certo (ou do que foram aconseIhados a tomar como certo). O processo de despolitização já mencionado deixa muito pouco espaço para a crítica de um discurso dominante, o que compromete cada vez mais a democracia. Em vez de tal discurso ser considerado uma perspectiva que privilegia certos interesses, ele vem a ser considerado como a única explicação verdadeira, questionando-se apenas os métodos mais eficazes de implementação. Nessa situação, opções de política e prática são reduzidas a questões técnicas limitadas e emprobrecidas do tipo "o que funciona melhor?" (para uma discussão mais completa sobre essa importante questão, ver Moss, 2007).

Finalmente, gostaria de mencionar mais um nível em que a prática democrática é necessária, além dos contextos nacional, regional, local e institucional: o europeu. A União Europeia tem uma longa história de envolvimento na política e no atendimento à primeira infância, embora tenha tendido a um discurso um tanto restrito sobre "cuidado da criança", já que seu interesse surgiu, principalmente, dos objetivos políticos do mercado de trabalho (incluindo a igualdade de gênero no emprego). Há dois exemplos recentes desse envolvimento e um terceiro onde a educação infantil deveria aparecer, mas não aparece.

Em 2002, em uma reunião em Barcelona, os governos da União Europeia concordaram que"os estados-membros [devem empenhar-se para] até 2010 oferecer atendimento a pelo menos $90 \%$ das crianças entre 3 anos e a idade da escolaridade obrigatória e a pelo menos $33 \%$ das crianças menores de 3 anos."Esse objetivo puramente quantitativo nada diz sobre a 
organização ou o conteúdo desses locais; nenhuma referência é feita, por exemplo, aos critérios acordados 10 anos antes pelos governos dos estados-membros quando adotaram uma Recomendação do Conselho sobre Cuidado de Crianças, que estabelecia uma série de princípios e objetivos para orientar o desenvolvimento qualitativo dos serviços. Ao invés disso, deixa-se para os estados-membros a busca de cumprimento das metas de Barcelona "em conformidade com os padrões [nacionais] de provisão".

Em abril de 2006, a chamada Bolkestein Directive - ou Diretiva de Serviços, para usar seu nome adequado - foi substancialmente alterada pelo Conselho Europeu e pelo Parlamento Europeu, abandonando o princípio de país de origem e excluindo os setores de serviços sociais e de saúde (inclusive atendimento às crianças). Sem essas modificações, essa proposta de legislação europeia da Comissão Europeia permitiria a provedores privados estabelecer creches em outros países, aplicando os padrões regulamentares do seu próprio país, e dessa forma arriscando um processo de nivelamento pelo denominador comum mais baixo (Szoc, 2006).

Em julho de 2006, a Comissão Europeia produziu a comunicação Towards an EU Strategy on the Rights of the Child, na qual propôs "estabelecer uma ampla estratégia para promover efetivamente e salvaguardar os direitos da criança nas políticas internas e externas da União Europeia". A boa notícia é que a União Europeia reconheceu sua obrigação de respeitar os direitos das crianças. A má notícia é que a comunicação pouco se compromete e nada diz sobre os direitos da criança nas políticas de "cuidado das crianças" da União Europeia, tais como as metas de Barcelona mencionadas anteriormente, políticas que até agora foram motivadas principalmente por objetivos políticos preocupados com emprego e igualdade de gênero.

Com algumas honrosas exceções, a comunidade da primeira infância na Europa falhou em se envolver com essas e outras iniciativas; não criamos nenhuma política europeia para a primeira infância, não criamos um "espaço democrático" para a discussão de iniciativas políticas provenientes da União Europeia e para a criação de demandas por novas iniciativas. Não me parece possível, tampouco eu gostaria de ver, uma abordagem europeia uniforme em todos os aspectos da política, provisão e prática da primeira infância. Não penso que seja possível nem desejável uma abordagem europeia uniforme a todos os aspectos da política, provisão e práticas relativas à primeira infância. Mas, a meu ver, é possível e desejável trabalhar, democraticamente, para identificar um conjunto de valores, princípios e objetivos consensuais para o atendimento da infância: em suma, desenvolver uma abordagem ou política europeia de educação infantil. Em apoio a essa proposição, remeto ao Quality Targets in Services for Young Children, um relatório elaborado por um grupo de trabalho constituído por 12 estadosmembros através de um processo democrático de consulta, discussão e negociação (E.C.Childcare Network, 1996). Quality Targets define 40 metas 
comuns a serem atingidas por toda a Europa em um período de 10 anos, para implementar os princípios e objetivos acordados pelos governos de estados-membros na recomendação do 1992 Council Recommendation on Childcare. Revendo recentemente esse documento, fiquei impressionado ao constatar como ele resistiu à passagem do tempo, e também como mostra o potencial da prática democrática para a definição de um referencial europeu para a educação infantil.

Durante o ano de 2007, Children in Europe - uma revista singular, multinacional e multilíngue - propõe-se a estimular o debate democrático dentro dos países membros da União Europeia sobre se devemos e podemos trabalhar na definição de uma abordagem europeia ao atendimento para crianças. A intenção é apresentar, para discussão e contestação, uma declaração propondo certos valores e princípios compartilhados. Children in Europe não estará começando do zero, mas construindo sobre fundações europeias já existentes, como o 1992 Council Recommendation on Childcare e o Quality Targets, assim como os inestimáveis relatórios da OECD Starting Strong (Organization for Economic Cooperation and Development, 2001, 2006). Espero que muitos outros participem do espaço democrático que a Children in Europe espera inaugurar, trazendo não só a política europeia para a creche, mas também a creche para a política europeia.

\title{
Bringing politics into the nursery: early childhood education as a democratic practice
}

\begin{abstract}
This paper explores the possibility that early childhood institutions can be, first and foremost, places of political practice - and specifically of democratic politital practice. The case for the primacy of democratic political practice in early childhood institutions is made more urgent by two visible developments in many countries today: the growth of political interest in early childhood education, leading to an expansion of services, and the need to revitalize democratic politics. As well as bringing democratic practice into the nursery, what this would mean and what conditions might enable it, the paper also considers democratic practice at other levels: not only the institutional one but also the national or federal, the regional and the local, and how each level can create 'democratic space'at other levels. The paper ends by considering four issues related to democracy in early childhood education, including paradigmatic diversity and the European level.
\end{abstract}

Keywords: Citizenship. Democratic practice. Early childhood education. Child day care. Political practice. 


\section{Introduire la politique aux institutions de la petite enfance: éducation des petites enfants en tant que pratique démocratique}

Résumé: Dans cet article nous précisons l'idée selon laquelle les institutions de la petite enfance peuvent être avant tout des lieux de la pratique politique, et en particulier de pratique démocratique. La question de la primauté de la pratique démocratique dans les institutions de la petite enfance devient urgente en raison de deux phénomènes présents aujourd'hui dans des nombreux pays: l'intérêt politique grandissant pour l'éducation des jeunes enfants qui mène à une augmentation des services de la petite enfance, et le besoin de ranimer les politiques démocratiques. Cet article porte sur la practique démocratique dans les services de la petite enfance, sa signification et les conditions qui la rendent possible, mais aussi à d'autres niveaux: pas seulement au niveau institutionel mais aussi aux niveaux national ou fédéral, régional et local, en se demandant comment chaque niveau peut créer "des espaces démocratiques" à d'autres niveaux. L'article termine avec quatre questions liées à la démocratie dans l'éducation de la petite enfance, dont le paradigme de la diversité et le niveau de l'Europe.

Mots-clés: Citoyenneté. Practique démocratique. Institution de la petite enfance. Crèche. Practique politique.

\section{Introducción de la política en las guarderías: la educación infantil como práctica democrática}

Resumen: Este artículo explora la posibilidad que las guarderías puedan ser, en primer lugar y sobre todo, lugares de prácticas políticas y especialmente de prácticas políticas democráticas. La necesidad de uma primacia de las prácticas políticas democráticas en las guarderías adquiere urgencia a partir de los desarrollos presentes hoy en día en muchos países: el creciente interés gubernamental en la educación infantil, conducente a una expansión de los servicios; y la necesidad de revitalizar las políticas democráticas. Junto a la introducción de las prácticas democráticas en las guarderías, lo que esto significaria y cuales condiciones se requieren, el artículo también considera las prácticas democráticas en otros niveles: no solo el institucional, sino también el nacional o federal, el regional y el local, y como cada nivel puede crear "espacios democráticos" para otros niveles. El artículo finaliza considerando cuatro temas relacionados com la democracia en la educación infantil, incluyendo la diversidad paradigmática y el nivel europeo.

Palabras clave: Ciudadanía. Práctica democrática. Institución parvularia. Jardines infantiles. Práctica política. 


\section{Referências}

Associació de Mestres Rosa Sensat. (2005). For a new public education system Barcelona, España: Autor.

Babich, B. E., Bergoffen, D. B., \& Glynn, S. V. (1995). On the idea of continental and postmodern perspectives in the philosophy of science. In B. E. Babich, D. B. Bergoffen \& S. V. Glynn (Eds.), Continental and postmodern perspectives in the philosophy of science (pp. 1-7). Aldershot, UK: Avebury.

Beck, U. (1998). Democracy without enemies. Cambridge: Polity Press.

Cagliari, P., Barozzi, A., \& Giudici, C. (2004). Thoughts, theories and experiences for an educational project with participation. Children in Europe, 1(6), 28-30.

Clark, A. (2005). Ways of seeing: Using the Mosaic approach to listen to young children's perspectives. In A. Clark, A. T. Kjørholt \& P. Moss (Eds.), Beyond listening: Children's perspectives on early childhood services (pp. 29-50). Bristol: Policy Press.

Clark, A., \& Moss, P. (2005). Spaces to play: More listening to young children using the Mosaic approach. London: National Children's Bureau.

Clarke, J. (1998). Thriving on chaos? Managerialisation and the welfare state. In J. Carter (Ed.), Postmodernity and the fragmentation of welfare (pp. 171-186). London: Routledge.

Dahlberg, G.., \& Moss, P. (2005). Ethics and politics in early childhood education. London: RoutledgeFalmer

Dahlberg, G.., Moss, P., \& Pence, A. (1999). Beyond quality in early childhood education and care: Postmodern perspectives. London: Falmer.

E. C. Childcare Network. (1996). Quality targets in services for young children. Brussels: European Commission Equal Opportunities Unit.

English Department for Education and Skills. Department for Work and Pensions. (2006a). Choice for parents, the best start for children: Making it happen. London: Department for Education and Skills.

English Department for Education and Skills. Department for Work and Pensions (2006b). The earlyyears foundation stage: Consultation on a single quality framework for services to children from birth to five. London: Department for Education and Skills.

Foucault, M. (1988). Politics, philosophy, culture: Interviews and other writings 19771984. New York: Routledge.

Hoyuelos, A. (2004). A pedagogy of transgression. Children in Europe, 1(6), 6-7.

Icelandic Ministry of Education, Science and Culture. (2003). National curriculum guide for pre-schools. Reykjavik: Author.

Luke, A. (2005). Curriculum, ethics, metanarrative: Teaching and learning beyond the nation. In Y. Nozaki, R. Openshaw \& A. Luke (Eds.), Struggles over difference: Curriculum, texts, and pedagogy in the Asia-Pacific (pp. 11-25). Albany: SUNY Press. 
Moss, P. (2007). Meetings across the paradigmatic divide. Educational Philosophy and Theory, 39(3), 229-245.

Norwegian Ministry of Education and Research. (2006). Framework plan for the content and tasks of kindergartens. Oslo: Ministry of Education and Research.

Oberhuemer, P. (2005). Conceptualizing the early childhood professional. Paper given to the 15th Annual EECERA Conference, Malta.

Organization for Economic Cooperation and Development. (2001). Starting strong. Paris: OECD.

Organization for Economic Cooperation and Development. (2006). Starting Strong II. Paris: OECD.

Power Inquiry. (2006). The report of power: An independent inquiry into Britain's democracy. London: The Power Inquiry.

Qualifications and Curriculum Authority. (2000). Curriculum guidance for the foundation stage. London: Author.

Rinaldi, C. (2005). In dialogue with Reggio Emilia: Listening, researching and learning. London: Routledge.

Rose, N. (1999). Powers of freedom: Reframing political thought. Cambridge: Cambridge University Press.

Santos, B. S. (2004). Interview with Boaventura de Sousa Santos. Globalisation, Societies and Education, 2(2), 147-160.

Swedish Ministry of Education and Science. (1998). Curriculum for preschool Stockholm: Author.

Szoc, E. (2006). From Bolkestein to social services of general interest. Children in Europe, 1(11), 6-7.

Wagner, J. T. (2006). An outsider's perspective: Childhoods and early education in the Nordic countries. In J. Einarsdottir, J. T. Wagner (Eds.), Nordic childhoods and early education: Philosophy, research, policy and practice in Denmark, Finland, Iceland, Norway, and Sweden (pp. 145-159). Greenwich, CT: Information Age.

Yeatman, A. (1994). Postmodern revisionings of the political. London: Routledge.

Peter Moss, Pesquisador do Thomas Coram Research Unit e Professor da área de Provisão da Primeira Infância, do Institute of Education, University of London, Reino Unido. Endereço para correspondência:Thomas Coram Research Unit, Institute of Education, University of London, 27/28 Woburn Square. London WC1H 0AA, Room 33. Endereço eletrônico: peter.moss@ioe.ac.uk

Recebido em: 19/02/2009

Aceito em: 18/05/2009 